\title{
Bragg Gratings Induced in Birefringent Optical Fiber with an Elliptical Stress Cladding
}

\author{
I. K. Meshkovskiy, V. E. Strigalev, A. V. Kulikov, and S. V. Varzhel' \\ Saint Petersburg National Research University of Information Technologies, Mechanics and Optics, Kronverkskiy Prospekt 49, \\ Saint Petersburg 197101, Russia
}

Correspondence should be addressed to S. V. Varzhel'; vsv187@gmail.com

Received 20 August 2013; Revised 17 November 2013; Accepted 17 November 2013

Academic Editor: Haroldo Hattori

Copyright (c) 2013 I. K. Meshkovskiy et al. This is an open access article distributed under the Creative Commons Attribution License, which permits unrestricted use, distribution, and reproduction in any medium, provided the original work is properly cited.

The paper presents the results of writing of type I and high-performance type II fiber Bragg gratings in birefringent optical fiber with an elliptical stress cladding by a single $20 \mathrm{~ns}$ pulse of $\mathrm{KrF}$ excimer laser $(248 \mathrm{~nm})$. The gratings' efficiency produced by a single pulse was up to $100 \%$. Experimental results on visualization of these gratings are presented.

\section{Introduction}

The first fiber Bragg grating (FBG) was obtained in 1978 [1]. About ten years later, FBG was written through a lateral surface of optical fiber for the first time [2]. Nowadays, gratings are becoming more and more widely used.

Fiber Bragg gratings written in birefringent optical fibers can be used in creation of sensors for measuring physical quantities $[3,4]$. To date, FBGs have been induced in birefringent optical fibers of different types: with elliptical core [5], bow-tie [6], PANDA [7], and internal elliptical cladding [8]. Here we demonstrate the results of FBG writing by a single $20 \mathrm{~ns} \mathrm{KrF}$ excimer laser pulse in birefringent optical fiber with an elliptical stress cladding, obtained using the technology $[9,10]$

This birefringent optical fiber due to its unique properties [11] is being used to create precision interferometric sensors, such as a fiber-optic gyroscope [12]. Special quadrupole winding is used in a fiber-optic gyroscope with the class of accuracy below $0.01 \mathrm{deg} / \mathrm{h}$ for temperature drift compensation in the fiber loop, which is the main source of phase noise [12].

To create a fiber-optic gyroscope with class of accuracy $0.01 \mathrm{deg} / \mathrm{h}$ and higher, the development of an active system of temperature gradients compensation in the fiber loop is required.
Refractive index gratings are being widely used in temperature sensors $[13,14]$. So, it is possible to measure temperature gradients inside the gyroscope fiber loop using FBGs array.

For creating FBGs array, this birefringent optical fiber with an elliptical stress cladding, obtained using the technology $[9,10]$ with complex structure [15], which includes a core, a circular isolating cladding, an elliptical stress cladding, and a circular outer cladding, was selected. To enhance the photosensitivity of the fiber the concentration of $\mathrm{GeO}_{2}$ in its core was increased to $16 \mathrm{~mol}$. \%. Enhancing the photosensitivity at the stage of preform formation allows you to write the FBG arrays during the drawing process of optical fiber. The disadvantage of this method is an increase in linear optical losses of the fiber. Losses of birefringent optical fiber with an elliptical stress cladding with $16 \mathrm{~mol}$. \% $\mathrm{GeO}_{2}$, used in this work, are $\sim 18 \mathrm{~dB} / \mathrm{km}$ at $1550 \mathrm{~nm}$. But losses of birefringent optical fiber with an elliptical stress cladding with 4 mol. $\% \mathrm{GeO}_{2}$, produced using the same technology $[9,10]$, are less than $1 \mathrm{~dB} / \mathrm{km}$ at a wavelength of $1550 \mathrm{~nm}$.

\section{Experimental Setup}

We used an excimer laser Lambda Physik Compex 102 with pulse energy $150 \mathrm{~mJ}$ using a gas mixture of KrF. FBG writing 


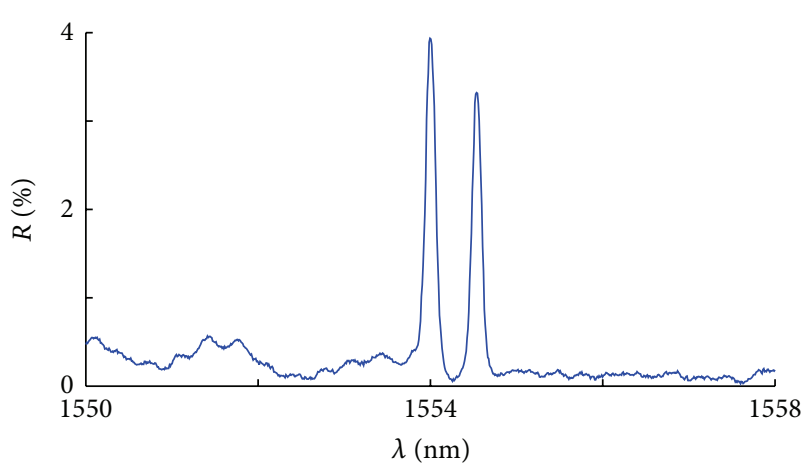

FIGURE 1: Type I FBG reflection spectrum.

scheme is shown in [16] and the attenuator with a built-in shutter was added at the laser output.

The laser generates $20 \mathrm{~ns}$ pulses at a wavelength of $248 \mathrm{~nm}$ with a frequency of $1 \mathrm{~Hz}$. The attenuator with a built-in shutter allows you to allocate a single pulse from their order, when the laser is launched into a stationary mode. The cylindrical lens focuses the laser beam on one axis to achieve the required energy density. The aperture allows changing the length of the grating.

A single 20 ns laser pulse, passing through a phase mask (PM) with a period $\Lambda_{\mathrm{PM}}=1065.3 \mathrm{~nm}$ and suppression of the zero-order diffraction $(<3 \%)$ at a wavelength of $248 \mathrm{~nm}$, is diffracted in +1 and -1 orders. The interference pattern of +1 and -1 orders writes the refractive index grating in the fiber core, fixed in the magnetic holder at the distance of several microns from the PM.

\section{Results}

Figure 1 shows the reflection spectrum of FBG, written with a single pulse in birefringent optical fiber with an elliptical stress cladding with $16 \mathrm{~mol} \% \mathrm{GeO}_{2}$. Presented FBG was written with the energy of $75.9 \mathrm{~mJ}$ at the attenuator output. The resulting FBG is a type I grating [17].

The presence of two reflection peaks in Figure 1 is due to the fact that the grating is induced in birefringent optical fiber. Since the effective refractive index for each of the selected axes of birefringent optical fiber is different, the wavelength of the Bragg resonance is different for the light traveling along the fast and slow axes of the fiber.

With a slight increase in energy at the attenuator output to $79.3 \mathrm{~mJ}$, so that the energy density on optical fiber is closer to $1 \mathrm{~J} / \mathrm{cm}^{2}$, type II grating [18] was written in the same fiber with a single excimer laser pulse. Figure 2 shows the spectra of the type II FBG: reflection (a) and transmission (b).

Type II FBG has about $100 \%$ reflection and the spectral width at half maximum over $1 \mathrm{~nm}$. Due to the broadening of the spectrum, reflection peaks of the two orthogonal polarizations are merged.

Investigation of the thermal stability and visualization of this FBG confirm that this is grating of type II, which can withstand high temperatures (up to $1000^{\circ} \mathrm{C}$ ) in contrast to the grating of type I. As shown by the authors in [19], type II FBG

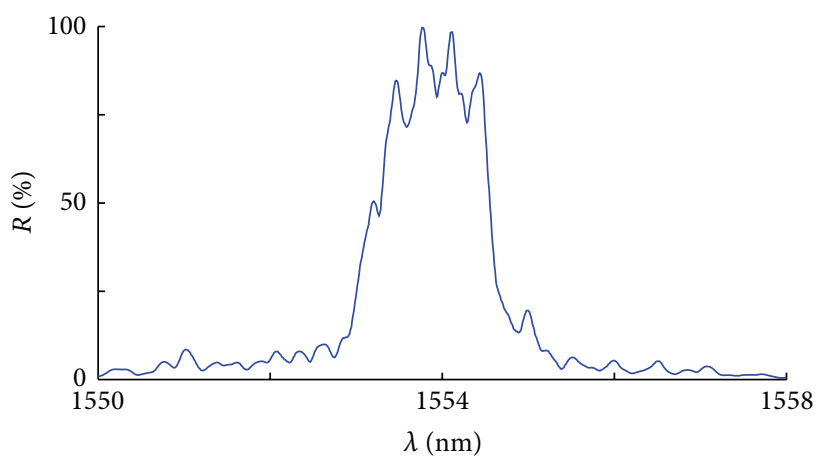

(a)

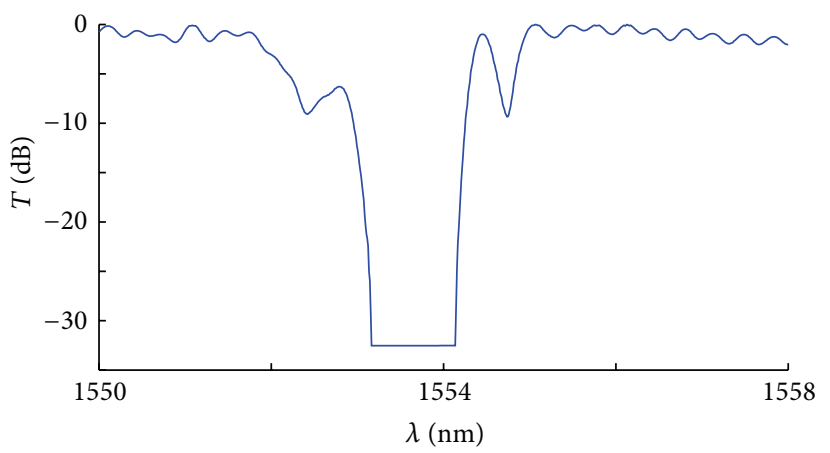

(b)

FIgURE 2: Type II FBG spectra: reflection (a) and transmission (b).

annealing begins only at $900^{\circ} \mathrm{C}$, which is consistent with the data presented in $[13,20]$.

Also the observed dependence of the induced grating type on the pulse energy is consistent with the experimental data presented in $[20,21]$.

\section{Visualization of Type II Fiber Bragg Gratings}

Visualization of type II FBGs induced in birefringent bow-tie optical fiber was presented in [6].

Experimental results on visualization of type II FBGs induced in birefringent optical fiber with an elliptical stress cladding with 12 and $18 \mathrm{~mol} . \% \mathrm{GeO}_{2}$ were presented in the previous work [22]. Here, we demonstrate visualization of type II FBG induced in birefringent optical fiber with an elliptical stress cladding with $16 \mathrm{~mol}$. $\% \mathrm{GeO}_{2}$ (Figure 3).

The FBG image was obtained by the optical microscope Zeiss AxioImager $\mathrm{Z} 1$ by the differential interference contrast (DIC) technique with a diode laser $(405 \mathrm{~nm})$. DIC measurements can be successfully used to obtain the refractive index profile of optical fiber [23]. The DIC technique is also used to get images of type I gratings [24].

The obtained images show that a single pulse recording of type II FBGs creates a periodical structure in optical fiber, the spatial period of which corresponds to the PM period, optimized for $+1 /-1$ diffraction orders. The measured period of the grating is about $1.06 \mu \mathrm{m}$. As seen in Figure 3, grating is not localized in the core of the optical fiber but 


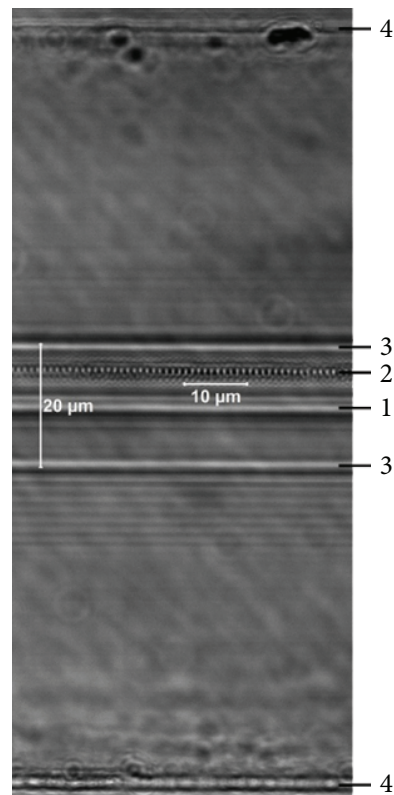

FIGURE 3: FBG image in birefringent optical fiber with an elliptical stress cladding with $16 \mathrm{~mol}$. $\% \mathrm{GeO}_{2}$, where 1 is core, 2 is heterogeneous periodical structure, 3 is boundary between $20 \mu \mathrm{m}$ cladding and stress cladding, and 4 is outer boundary of the fiber.

near the boundary between the core and the $20 \mu \mathrm{m}$ cladding. However, despite the fact that this should lead to a lower efficiency of the FBG, this grating has an almost $100 \%$ reflection (Figure 2). Perhaps this is due to energy transfer from the fundamental core mode into the modes of elliptical cladding, but the exact explanation of this fact requires further research.

\section{Conclusion}

Type I and type II FBGs were written in birefringent optical fiber with an elliptical stress cladding by a single $20 \mathrm{~ns}$ pulse of $\mathrm{KrF}$ excimer laser $(248 \mathrm{~nm})$. The gratings' efficiency produced by a single pulse was up to $100 \%$. Experimental results on visualization of type II FBGs show the localization of these gratings in this fiber type.

The obtained FBGs can be used not only in temperature sensors but also in creation of a new generation of measurement systems, such as fiber-optic hydrophone or monitoring system of extent objects (pipelines, railways, and borders). Distinctive features of these systems are the extension of controlled areas, speed, and unique information capabilities.

\section{Conflict of Interests}

The authors declare that there is no conflict of interests regarding the publication of this paper.

\section{Acknowledgments}

The authors thank M. A. Eron'yan and K. V. Dukel'skiu for the samples of birefringent optical fiber with an elliptical stress cladding doped with 16 mol. $\% \mathrm{GeO}_{2}$ and useful discussions in the course of this work. This work was done in NRU ITMO and was supported by the Ministry of Education and Science of the Russian Federation under the Project 02.G25.31.0044.

\section{References}

[1] K. O. Hill, Y. Fujii, D. C. Johnson, and B. S. Kawasaki, "Photosensitivity in optical fiber waveguides: application to reflection filter fabrication," Applied Physics Letters, vol. 32, no. 10, pp. 647-649, 1978.

[2] G. Meltz, W. W. Morey, and W. H. Glenn, "Formation of Bragg gratings in optical fibers by a transverse holographic method," Optics Letters, vol. 14, no. 15, pp. 823-825, 1989.

[3] A. Othonos, "Fiber Bragg gratings," Review of Scientific Instruments, vol. 68, no. 12, pp. 4309-4341, 1997.

[4] S. Bette, C. Caucheteur, M. Wuilpart, and P. Mégret, "Theoretical and experimental study of differential group delay and polarization dependent loss of Bragg gratings written in birefringent fiber," Optics Communications, vol. 269, no. 2, pp. 331-337, 2007.

[5] G. Meltz and W. W. Morey, "Bragg grating formation and germanosilicate fiber photosensitivity," in International Workshop on Photoinduced Self-Organization Effects in Optical Fiber, vol. 1516 of Proceedings of SPIE, pp. 185-199, Québec, Canada, December 1991.

[6] P. C. Hill, G. R. Atkins, J. Canning, G. C. Cox, and M. G. Sceats, "Writing and visualization of low-threshold type II Bragg gratings in stressed optical fibers," Applied Optics, vol. 34, no. 33, pp. 7689-7694, 1995.

[7] I. Abe, R. E. De Góes, J. L. Fabris et al., "Production and characterization of refractive index gratings in high-birefringence fibre optics," Optics and Lasers in Engineering, vol. 39, no. 5-6, pp. 537-548, 2003.

[8] I. Abe, H. J. Kalinowski, R. Nogueira, J. L. Pinto, and O. Frazão, "Production and characterisation of Bragg gratings written in high-birefringence fibre optics," IEE Proceedings-Circuits, Devices and Systems, vol. 150, no. 6, pp. 495-500, 2003.

[9] M. A. Eron'yan, "Method of fabricating fiber lightguides that maintain the polarization of the radiation," Russian Patent no. 2155359, 2000.

[10] S. V. Bureev, K. V. Dukel'skiǐ, M. A. Eron'yan et al., "Processing large blanks of anisotropic single-mode lightguides with elliptical cladding," Journal of Optical Technology, vol. 74, no. 4, pp. 297-298, 2007

[11] S. V. Bureev, I. K. Meshkovskiǐ, E. Yu. Utkin et al., "Minimizing the optical losses in anisotropic single-mode lightguides with elliptical boron germanosilicate cladding," Journal of Optical Technology, vol. 79, no. 7, pp. 433-436, 2012.

[12] I. K. Meshkovsky, V. Y. Strigalev, G. B. Deineka, V. G. Peshekhonov, D. V. Volynsky, and A. A. Untilov, "Three-axis fiber-optic gyroscope: development and test results," Gyroscopy and Navigation, vol. 2, no. 4, pp. 208-213, 2011.

[13] H. Bartelt, K. Schuster, S. Unger, C. Chojetzki, M. Rothhardt, and I. Latka, "Single-pulse fiber Bragg gratings and specific coatings for use at elevated temperatures," Applied Optics, vol. 46, no. 17, pp. 3417-3424, 2007.

[14] Y. Zhan, H. Wu, Q. Yang, S. Xiang, and H. He, "Fiber grating sensors for high-temperature measurement," Optics and Lasers in Engineering, vol. 46, no. 4, pp. 349-354, 2008. 
[15] A. G. Andreev, I. I. Kryukov, T. V. Mazunina et al., "Increasing the birefringence in anisotropic single-mode fiber lightguides with an elliptical stress cladding," Journal of Optical Technology, vol. 79, no. 9, pp. 608-609, 2012.

[16] S. V. Varzhel', A. V. Kulikov, I. K. Meshkovskii, and V. E. Strigalev, "Recording Bragg gratings in a birefringent optical fiber with a single 20-ns pulse of an excimer laser," Journal of Optical Technology, vol. 79, no. 4, pp. 257-259, 2012.

[17] J. Canning, "Fibre gratings and devices for sensors and laser," Laser \& Photonics Reviews, vol. 2, no. 4, pp. 275-289, 2008.

[18] S. A. Vasil'ev, O. I. Medvedkov, I. G. Korolev, A. S. Bozhkov, A. S. Kurkov, and E. M. Dianov, "Fibre gratings and their applications," Quantum Electronics, vol. 35, no. 12, pp. 1085-1103, 2005.

[19] S. V. Varzhel', A. V. Kulikov, K. A. Konnov, and A. I. Gribaev, "Single excimer pulse writing of Bragg gratings in birefringent optical fiber with an elliptical stress cladding: visualization and thermal annealing of the gratings," in Proceedings of the Materials of the 5th International Research and Practice Conference, vol. I, pp. 305-310, Munich, Germany, October 2013.

[20] L. Reekie, J. L. Archambault, and P. S. J. Russell, "100\% reflectivity fibre gratings produced by a single excimer laser pulse," in Proceedings of the Optical Fiber Communication Conference, OSA Technical Digest Series, paper PD14, pp. 327-330, San Jose, Calif, USA, February 1993.

[21] B. Malo, D. C. Johnson, F. Bilodeau, J. Albert, and K. O. Hill, "Single-excimer-pulse writing of fiber gratings by use of a zero-order nulled phase mask: grating spectral response and visualization of index perturbations," Optics Letters, vol. 18, no. 15, pp. 1277-1279, 1993.

[22] S. V. Varzhel', V. V. Zakharov, G. N. Vinogradova, A. V. Veniaminov, and V. E. Strigalev, "Visualization of type II fiber Bragg gratings Induced in a birefringent fiber with an elliptical stress cladding," Optics and Spectroscopy, vol. 114, no. 1, pp. 116119, 2013.

[23] B. Kouskousis, D. J. Kitcher, S. Collins, A. Roberts, and G. W. Baxter, "Quantitative phase and refractive index analysis of optical fibers using differential interference contrast microscopy," Applied Optics, vol. 47, no. 28, pp. 5182-5189, 2008.

[24] N. M. Dragomir, C. Rollinson, S. A. Wade et al., "Nondestructive imaging of a type I optical fiber Bragg grating," Optics Letters, vol. 28, no. 10, pp. 789-791, 2003. 

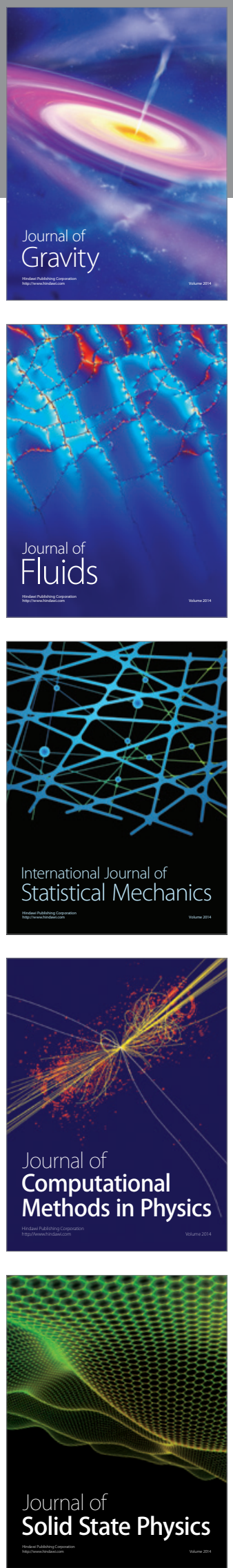

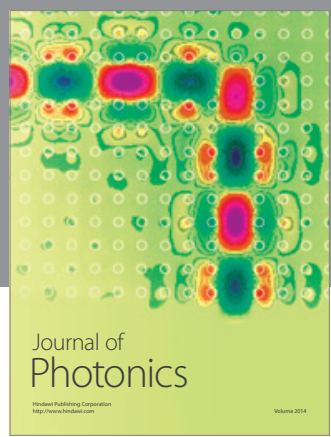

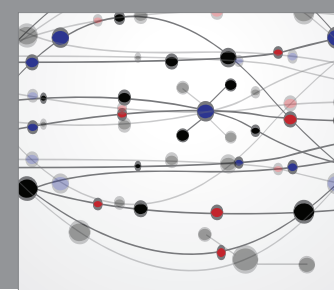

The Scientific World Journal

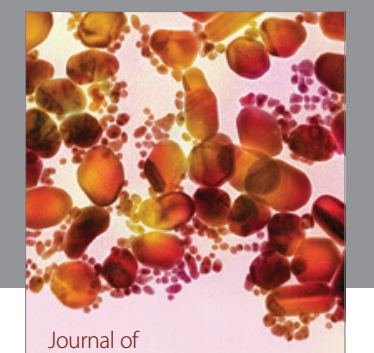

Soft Matter
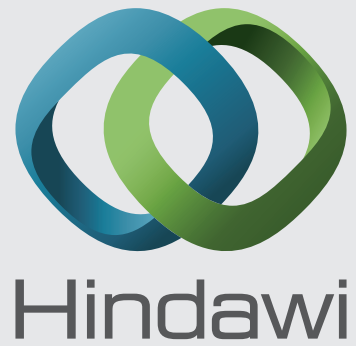

Submit your manuscripts at

http://www.hindawi.com
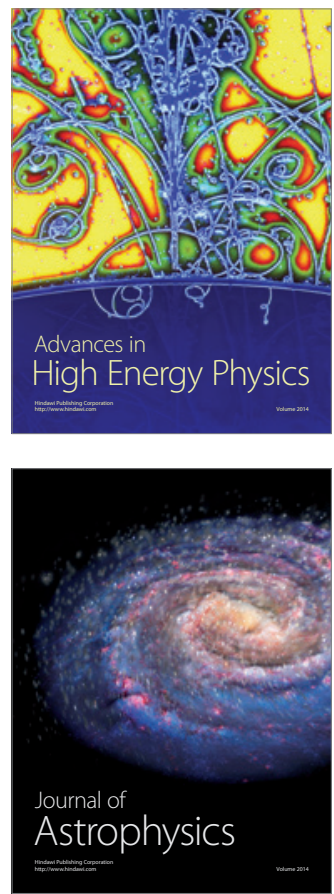
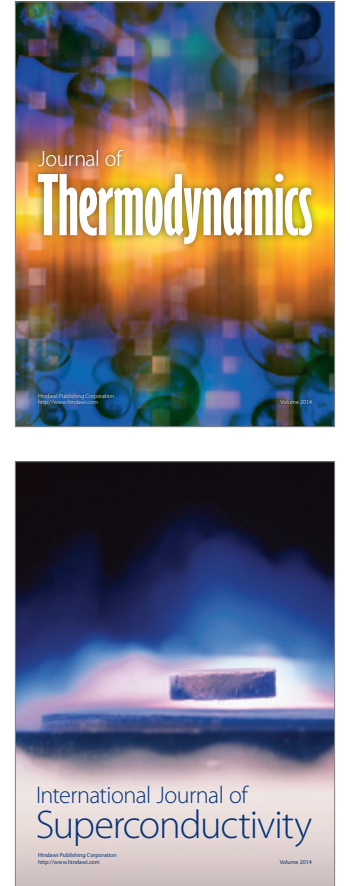
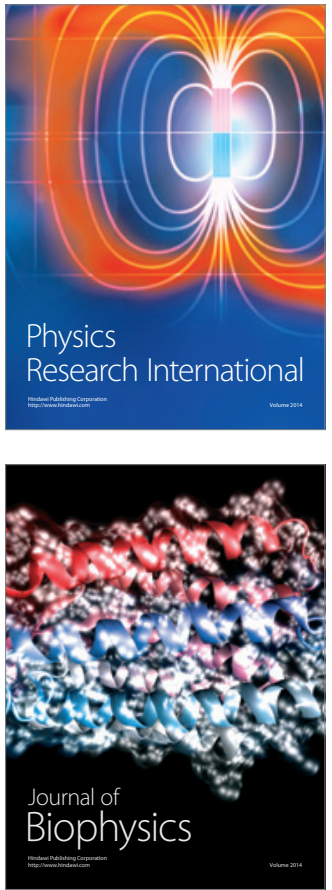
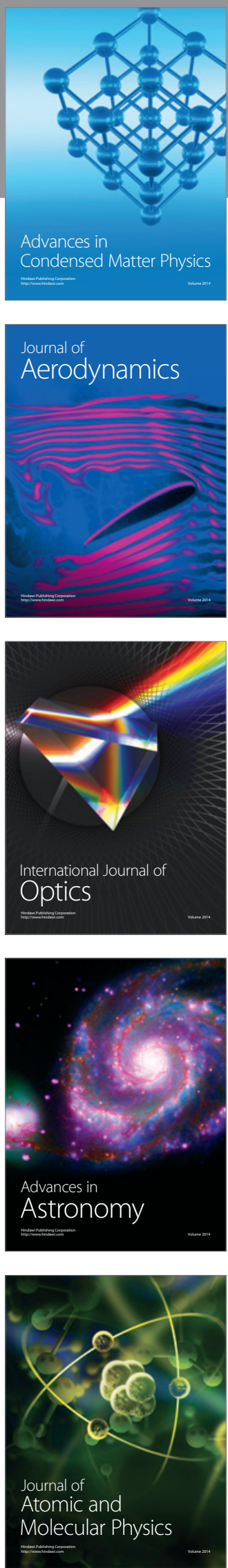